\title{
Organizações internacionais como aparato de produção simbólica do Estado: - caso da Organização do Tratado de Cooperação Amazônica (OTCA)
}

\author{
Internationalorganizationsasstatesymbolicproduction \\ apparatus: the case of the Amazon Cooperation Treaty \\ Organization (ACTO)
}

\section{Daniela Caruza Gonçalves Ferreira}

Professora do Instituto Federal de Educação, Ciência e Tecnologia do Piauí (IFPI). Doutora em Ciências Sociais pela Universidade do Estado do Rio de Janeiro (UERJ). ID ORCID: https://orcid.org/00000002-4370-6519.

\section{RESUMO}

As organizações internacionais interestatais têm proliferado nas últimas décadas como um instrumento de governo apropriado para tratar questões definidas como de interesse público que atravessam as fronteiras nacionais historicamente estabelecidas. Sua constituição jurídica lhes assegura um lugar privilegiado como sujeitos de uma esfera pública internacional, enquanto a composição de um quadro burocrático próprio, de funcionários públicos internacionais que atuam especialmente através do desenvolvimento de projetos de cooperação, lhes confere caráter eminentemente técnico, autônomo e despolitizado. A partir da análise do processo de constituição e dos modos de operar da Organização do Tratado de Cooperação Amazônica (OTCA), única organização internacional sediada no Brasil, coloco em perspectiva tais imaginários difundidos acerca da forma "organização internacional". Ao examinar a centralidade da produção discursiva e ritual em seu âmbito, acessada por meio de exame de documentos de caráter público e sigiloso, observo como seus enunciados, que aparentam conter compromissos do Estado para a consecução de finalidades específicas, podem ser entendidos como uma performance da própria capacidade estatal de enunciar domínios sobre territórios e populações, situando-os como parte da disputa pelo poder de definir destinos, sob o nome de "políticas".

Palavras-chave: Organização do Tratado de Cooperação Amazônica; Organização Internacional; Performance de Estado.

\section{ABSTRACT}

International interstate organizations began to propagate in recent decades as a proper instrument of government, suitable to address questions defined as public issues that intersect historically established national borders. Their legal framework assures them privileged position as subjects of 
an international public sphere, while the composition of a bureaucratic board of its own, formed by international public officials who operate specially through the development of cooperation projects, provides them eminently technical, autonomous and depoliticized aspects. In this paper these widely spread imaginaries about international organizations are put into perspective through the analysis of the constitution processes and modes of operation of the Amazon Cooperation Treaty Organization, the only international organization based in Brazil. By recognizing the centrality of its ritual practices and discursive production, attained through the analysis of documents of public and secret character, I observe how statements and declarations within the Organization which appear to contain State commitments for the achievement of specific purposes can be understood as a performance of the State's very own capacity to enunciate domains over populations and territories.

Keywords: Amazon Cooperation Treaty Organization, International Organizations, State Performance.

As organizações internacionais vêm operando intensos fluxos de dinheiro, de ideias, de pessoas e de poder na atualidade. Suas prescrições e atuações, articuladas e decididas em conjunto, se revestem de um caráter de abrangência que parece englobar todos os territórios e populações do mundo. Para os países que, juntos, as criam ou delas participam, compor ou, mais especialmente, conceber e sediar uma organização internacional é uma iniciativa considerada indício de sucesso e prestígio estatal, apontando para as capacidades de cooperar e produzir consensos para a resolução de questões definidas como problemas públicos que atravessam fronteiras nacionais.

Como objeto de estudo, as organizações internacionais têm sido mais comumente abordadas pelo campo disciplinar das relações internacionais. A antropologia, por sua vez, reverberando sua vocação clássica, tem se voltado especialmente ao estudo dos efeitos de suas políticas, programas e projetos sobre as populações. Apresento, neste artigo, alguns questionamentos acerca das percepções instituídas sobre essas composições políticas interestatais, sublinhando seus efeitos como aparato simbólico de produção do poder do Estado.

Tomo como parâmetro para as reflexões ora apresentadas a pesquisa sobre a Organização do Tratado de Cooperação Amazônica (OTCA), organização internacional sediada no Brasil, formada por oito países da América do Sul - Bolívia, Brasil, Colômbia, Equador, Guiana, Peru, Suriname e Venezuela - cujo objetivo declarado é incentivar o desenvolvimento sustentável e a inclusão social da região amazônica, apresentando-se como uma autoridade no que diz respeito à definição e execução de uma agenda internacional de proteção ambiental e desenvolvimento para a Amazônia. A Organização 
completa 20 anos em 2018, e o Tratado de Cooperação Amazônica (TCA), acordo político que lhe dá origem e nome, faz 40 anos. Seus países-membros seguem comprometendo-se com a sua existência, o que sugere que a sua manutenção é considerada importante.

Entendo o que está sendo produzido através de sua atuação não somente como "efeitos concretos" de projetos estratégicos, de acordo com seus objetivos declarados - quando o são. O que está sendo produzido de mais importante por meio da criação e atuação de uma organização internacional interestatal como a OTCA é a própria ideia de Estado e sua capacidade de enunciar domínio sobre territórios e populações.

A pesquisa foi realizada principalmente através de uma etnografia baseada em documentos ${ }^{1}$, tendo em conta a importância das práticas desses escritos para o contexto considerado. Os enunciados e sua inscrição em documentos são os mais importantes e recorrentes procedimentos no âmbito da OTCA. Os materiais explorados na investigação incluem documentos públicos e sigilosos, produzidos para circulação externa e interna, com temporalidades muito distintas, reunidos como resultado de cinco anos de coleta e análise. Dos efeitos mágicos do ritual secular de produção de documentos pelas burocracias estatais e interestatais, destaco, por um lado, a fé que depositamos nas narrativas neles inscritas, tomadas como "dado", e, por outro, a aparente redundância da profusão de produções textuais desse tipo que, supostamente, tratam das "mesmas coisas". Categorizá-los e compreender os seus efeitos não era inicialmente um intuito em si, mas acabou se tornando, o que me possibilitou observar uma série de questões a respeito de práticas burocráticas.

\section{ORGANIZAÇÕES INTERNACIONAIS COMO CATEGORIA JURÍDICA}

Antes de qualquer coisa, é preciso compreender o que significa a designação de uma instituição como "organização internacional". Embora esse termo pareça aludir a uma categoria explicativa em si, que implicaria deter-

Para fazer uma etnografia baseada em documentos, inspirei-me nas reflexões de Lacerda (2015), Vianna (2014), Lugones (2017), Ferreira (2014), Anders (2005) e Das (2004). 
minada configuração e significância institucional, além de características essenciais, como "autonomia", trata-se, antes, da atribuição de uma categoria jurídica cunhada no campo do direito internacional para nomear alguns tipos de arranjos institucionais sob a figura formal de uma pessoa jurídica, o que, na prática, abarca uma infinidade de composições empíricas muito variadas. A despeito do efeito unificador que produz (e que reflete um senso comum arraigado sobre organismos de cunho transnacional), a categoria intitula sob uma mesma nomenclatura instituições bastante distintas em termos de porte, tamanho, influência, objetivos, esfera de atuação e tipos de atividades desenvolvidas, entre outros aspectos, de modo que não é possível deduzi-los, nem supor amplas semelhanças entre elas somente a partir dessa designação comum, o que também resulta em uma série de desafios para sua análise como formato político-administrativo de representação e governo.

A categoria abrange desde organizações relativamente pequenas, como a OTCA - que tem um orçamento anual de alguns milhões, e cuja constituição limita seu raio de atuação a porções específicas dos territórios de seus oito países-membros -, até outras gigantescas, compostas por centenas de nações e dotadas de megaburocracias, que vêm ocupando funções centrais no sistema interestatal devido ao seu acúmulo de capital político e financeiro, sendo capazes de influenciar consideravelmente os rumos de políticas nacionais e internacionais, a exemplo do Banco Mundial, Fundo Monetário Internacional (FMI) e da própria Organização das Nações Unidas (ONU) (ABBOTT; SNIDAL, 1998; GÓES FILHO, 2003)².

$\mathrm{O}$ processo de instituição da personalidade jurídica à qual se refere essa categoria se dá através de procedimentos cuja origem é atribuída a um

\footnotetext{
A amplitude da abrangência da categoria formal "organização internacional" se apresenta como uma questão no interior do próprio campo das relações internacionais, como demonstra a análise produzida por Abbott e Snidal (1998), pesquisadores dos campos disciplinares do direito internacional e relações internacionais, respectivamente, que buscam refletir sobre os motivos pelos quais os Estados, inclusive os mais poderosos, passaram a agir através de organizações internacionais com os mais variados aspectos. Os autores partem do pressuposto de que tais organizações são utilizadas (funcionalmente) pelos "Estados" para gerenciar suas interações cotidianas ou conflitos internacionais, investigando as funções que desempenham e as propriedades comuns que lhes permitiriam exercê-las, com foco no que chamam de "operações concretas" das organizações. Chegam à conclusão de que os "Estados", em certas circunstâncias, preferem aderir à utilização de organizações internacionais diante de outras alternativas de institucionalização da cooperação pelas suas propriedades de centralização e independência, que os autores consideram inerentes à forma, o que as capacitaria para, além de atuar na política mundial como "agentes autônomos", promover um "fórum neutro e especializado", resguardado da intrusão das altas políticas, visão que predomina nesse campo.
} 
ato jurídico, estatal e solene - a assinatura, por representantes legítimos de Estados Nacionais (ou de outras organizações porventura já instituídas), de um tratado internacional, ou seja, um documento escrito que materializa um acordo político entre dois ou mais países, e que é considerado seu "registro de nascimento". Não é fortuito que as organizações internacionais se originem a partir desse tipo de documento. Nem todos os acordos internacionais são formalizados por meio da assinatura de tratados, apenas aqueles aos quais se pretende atribuir particular importância política (BRASIL, 2012). Nesse sentido, é importante destacar que esses instrumentos são uma forma jurídica acionada há séculos, tendo como efeito último a consubstanciação de narrativas legitimadoras de domínios territoriais - uma materialidade fundamental dos Estados - e, consequentemente, de configurações da ordem política mundial (FERREIRA, 2018).

A origem da OTCA remete à assinatura de um tratado que, a princípio, não previa sua criação. As iniciativas e responsabilidades nele contempladas foram inicialmente atribuídas às burocracias nacionais dos próprios países signatários, "livrando-o de órgãos intrarregionais permanentes" (BRASIL, 1976), um posicionamento que pode ser observado em documentos de circulação interna do governo brasileiro, os quais registram seus procedimentos de negociação ${ }^{3}$. Os preparativos desse acordo haviam sido iniciados dois anos antes de sua assinatura, em 1976, envolvendo reuniões introdutórias,

3 É importante destacar que os mecanismos de produção de um tratado internacional - um acordo político de certa envergadura que se materializa em um documento revestido de valor, não tão somente pelo seu conteúdo mas por seu formato e pelos agentes que o enunciam - se tornam observáveis a partir e através da produção e circulação de outros tipos documentos. Um conjunto de documentos do Ministério das Relações Exteriores brasileiro, datados do período da gestão do chanceler Antônio Francisco Azeredo da Silveira, encontra-se disponível on-line para ampla consulta no acervo de arquivos pessoais do Centro de Pesquisa e Documentação de História Contemporânea do Brasil da Fundação Getúlio Vargas - CPDOC/FGV. Os documentos consultados para o desenvolvimento desta pesquisa encontram-se na subsérie Assuntos Interamericanos do arquivo de Silveira.

Fonte: FVG CPDOC. AAS mre ai 1977.03.02. Documentos referentes à proposta e institucionalização do Pacto Amazônico durante a gestão de Azeredo da Silveira como ministro das Relações Exteriores. Tratam da proposta brasileira aos países amazônicos - Bolívia, Colômbia, Equador, Guiana, Peru, Suriname e Venezuela - de celebração de um tratado para a região abrangendo as áreas de navegação, interconexão rodoviárias, ferroviárias e fluviais, assistência técnica, proteção da flora e fauna, turismo, entre outras; e das negociações em torno da proposta, que se concretizou na assinatura do tratado, no dia 03 de julho de 1978. In: FGV CPDOC. Acervo. Rio de Janeiro: FGV, [1977-1979]. Disponível em: http://www.fgv.br/cpdoc/acervo/arquivo-pessoal/AAS/textual/documentos-referentes-a-proposta-e-institucionalizacao-do-pacto-amazonico-durante-a-gestao-de-azeredo-da-silveira-como-ministro-das-relacoes-exter. Acesso em: 24 mai. 2016. 
gestões diplomáticas ${ }^{4}$ e negociações bilaterais, além de um minucioso trabalho retórico, que foi elaborado considerando as possíveis implicações dos enunciados. Um exemplo foi a supressão ou substituição de expressões originalmente presentes no texto proposto pelo governo brasileiro que pudessem gerar interpretações suscetíveis de serem mobilizadas para justificar conflitos políticos e militares, tais como "defesa", "segurança", "defesa de integridade". Por solicitação das delegações diplomáticas dos demais países foram adotados outros termos, considerados mais propícios à conciliação de interesses, como "desenvolvimento harmônico" (BRASIL, 1978).

O tratado foi pessoalmente assinado, em 1978, pelos presidentes dos doravante "países amazônicos", acompanhados de suas respectivas delegações diplomáticas, em solenidades realizadas em Brasília ao longo de dois dias. Os eventos incluíram, além da cerimônia de assinatura propriamente dita, discursos, banquetes e uma Condecoração dos Chanceleres dos Países Amazônicos, ocasiões nas quais foi celebrada a importância política do acordo em questão (BRASIL, 1978b). Sob a alegação da ameaça da "cobiça internacional" e acionando o então emergente argumento da proteção ambiental, o TCA, no momento de sua assinatura, cumpriu seu papel como um instrumento de defesa da soberania nacional dos países amazônicos no campo das relações internacionais ${ }^{5}$ (TORRECUSO, 2004). É curioso notar que, embora constituindo o seu propósito político central, a soberania nacional figurava no texto do tratado não como um "objetivo" a ser alcançado, mas como um pressuposto, a partir do qual compromissos estatais para a consecução de finalidades específicas foram enunciados. Nesse sentido, destaco o procedimento de afirmação da soberania nacional através de expedientes como documentos e eventos solenes para sua construção como um dado essencial dos Estados.

\footnotetext{
Na diplomacia, o termo "gestão" é utilizado para designar negociações diretas com representantes diplomáticos de outros países e/ou organismos internacionais, no sentido de persuasão a respeito de questões específicas de interesse daqueles que as empreendem.

5 A figura da cobiça internacional em relação a territórios amazônicos como motivador político não foi uma novidade inaugurada com o TCA, mas o referido tratado a atualiza em termos de uma ameaça comum de internacionalização da região sob pretextos ecológico-ambientais (BRASIL, 1976) que torna plausível a reunião de determinados países - os quais tinham vínculos políticos irregulares e assimétricos entre si e com a comunidade internacional - em torno de um "mesmo interesse".
} 
Após 20 anos de vigência do tratado, sob o argumento de conferir-lhe mais "concretude", a criação de um organismo próprio para operacionalizar suas finalidades foi oficializada através da assinatura de um Protocolo de Emenda em $1998^{6}$ (OTCA, 2012a), vindo a ser gradualmente materializada nos anos seguintes por meio de outros atos, como um Acordo de Sede, fundamentado em 2002, entre uma já instituída OTCA e o governo brasileiro, que estabelece a instalação da sua Secretaria Permanente em Brasília. A história do TCA e da OTCA tem sido contada em seu próprio âmbito como um crescente e linear processo de "evolução". Isso ocorre no sentido de torná-los mais "efetivos" para a consecução dos seus objetivos declarados. Essa linearidade e o encadeamento de fatos são algo que só pode chegar a ser narrado a posteriori. Diferente do que se deu com a assinatura do TCA, as negociações para criação da OTCA foram muito mais alongadas e trabalhosas ${ }^{7}$, sugerindo que há implicações mais complexas quando se trata da instituição de uma nova personalidade jurídica no direito internacional. Os pontos discutidos no processo foram os objetivos da Secretaria Permanente, a autonomia do organismo e sua manutenção financeira ${ }^{8}$ (TCA, 2002).

De fato, a criação de uma organização internacional tem desdobramentos diferentes daqueles que resultam da assinatura de um tratado. O reconhecimento formal de uma personalidade autônoma na esfera internacional implica, em termos legais, a prescrição da capacidade de estabelecer, por

\footnotetext{
O Protocolo de Emenda alterou o artigo XXII do tratado para dar-lhe, constitucionalmente, uma Secretaria Permanente, cuja criação havia sido enunciada anteriormente através de uma resolução (RES/V MRE/1). Foi assinado em dezembro de 1998, em Caracas, Venezuela, pelos embaixadores dos países signatários. Não foi possível encontrar nos documentos consultados, públicos ou sigilosos, descrição das circunstâncias em que se deu este evento, nem os motivos que levaram à escolha dessa data.

7 A possibilidade de criação de uma Secretaria Permanente para o TCA foi mencionada em suas instâncias oficiais desde pelo menos 1989 (Declaração de São Francisco de Quito, 1989). Não obstante, ao mencionar as negociações envolvidas em sua instituição e instalação, me refiro a uma gama de reuniões realizadas por um Grupo de Trabalho ad hoc criado especialmente com essa finalidade. O Grupo permaneceu em operação de 1996 a 2002, tendo realizado oito reuniões, registradas em atas disponíveis na Base Jurídica do TCA (TCA, 2002), as quais analisei em conjunto com documentações internas produzidas no mesmo período. Assim, o processo de negociação estrita no âmbito do tratado para criação e instalação da OTCA e ativação de sua SP levou, no total, oito anos.

8 É curioso perceber nas atas, nesse sentido, registros de momentos de "amplo intercâmbio de opiniões", que se referem a dissidências, desacordos e aos procedimentos de negociação acionados para a produção de posições passíveis de aprovação. É curioso perceber como os conflitos são discursivamente apresentados sob um termo que alude à reciprocidade de relações e trocas mútuas, apontando sempre para um consenso presumido (TCA, 2002).
} 
si própria, relações jurídicas com outros entes nacionais e internacionais ${ }^{9}$, como celebrar acordos (inclusive novos tratados internacionais), contratar, adquirir e vender bens e comparecer em juízo (LAMY, 2015, p. 83). A operação da ideia de um agente distinto e com subjetividade própria se dá através de procedimentos objetivos de fabricação, em termos formais e materiais, da sua personalidade, numa composição de caracteres que produz um efeito de estrutura $^{10}$ : a instituição de um órgão com função de secretaria permanente, a construção de uma sede física, a formação de corpos burocráticos próprios, a realização de reuniões envolvendo autoridades diplomáticas (que dão materialidade aos acordos realizados, ainda que estes não cheguem a se desdobrar em ações diretas sobre o território tal como exposto em seus enunciados), a criação de um orçamento próprio. Sua origem é, portanto, estatal, e o seu funcionamento envolve a ativação de importantes estruturas análogas, embora as organizações internacionais não sejam, precisamente, Estado.

Além das materialidades mencionadas acima, é notável a intensa e extensa produção documental sobre a sua própria atuação, tais como declarações, resoluções e regulamentos, atas de reunião, planos de trabalho e relatórios de atuação, entre outros. A produção de diferentes tipos de documentos, de tal forma, tem a intenção explícita de comunicar e produzir para a existência ${ }^{11}$. No âmbito da OTCA, entende-se que a sua atuação deve ser informada por preceitos específicos, dispostos em uma série de documentos considerados referenciais. As características gerais e atribuições de cada

\footnotetext{
9 Algo explicitamente admitido, por exemplo, no artigo $1^{\circ}$ do Protocolo de Emenda ao TCA, que cria a OTCA “dotada de personalidad jurídica, siendo competente para celebrar acuerdos con las Partes Contratantes, con Estados no miembros y con otras organizaciones internacionales" (OTCA, 2012a).

${ }^{10}$ Utilizo a expressão "efeito de estrutura" numa referência às reflexões produzidas por Mitchell (2006) sobre o Estado, que ressalta, dentre os seus efeitos, a aparência de uma estrutura estável, contínua e duradoura, aparentemente externa às práticas operadas em seu âmbito. Como o autor sugere, a ideia que se tem do que seja o "Estado" é mais que uma crença subjetiva, é uma representação reproduzida em formas cotidianas visíveis. Sob esse efeito estruturante, o Estado opera de várias maneiras, nem sempre articuladas a priori, mas encadeadas através de diferentes táticas - nomeação, renomeação, apropriação, reconfiguração, entre outras.

${ }^{11}$ A produção de documentos por burocracias nacionais ou internacionais em diferentes formatos e com variados conteúdos não é uma mera formalidade, como demonstra Anders (2005) ao analisar a fabricação, através da prática de produção de documentos, de uma "despolitização" de instituições financeiras internacionais - Banco Mundial e FMI - e da ideia de autonomia dos países receptores. Estes, conforme os documentos comutados sugerem, não apenas "aceitam", mas "solicitam" intervenções dessas agências.
} 
uma de suas instâncias de atuação são definidas, principalmente, através do formato regulamento (regulamento da Reunião de Ministros Das Relações Exteriores - MRE, regulamento do Conselho de Cooperação Amazônica CCA, regulamento da Comissão de Coordenação do Conselho de Cooperação Amazônica - CCOOR, regulamento da Secretaria Permanente - SP, regulamento de pessoal da $\mathrm{SP}$ ), que, por meio da prescrição de seus papéis, as instituem, formalizando sua existência.

Por sua vez, a capacidade de tratar questões as quais a instituição se torna apta a nomear é materializada burocraticamente a partir de sua formação e através da composição de um quadro de funcionários especialistas técnicos e da produção e publicação de documentos de cunho executivo, tais como planos, programas e projetos, além de seus produtos - relatórios, manuais, entre outros. A Agenda Estratégica é considerada uma referência para a atuação da OTCA porque contém uma espécie de tradução, em termos presumidamente mais operacionais, de questões correspondentes a assuntos nomeados no TCA. Tais ideias podem vir a ser contempladas nas "propostas", "iniciativas", "acordos", "programas" e "projetos" desenvolvidos no âmbito da OTCA (pela Secretaria Permanente). A Agenda Estratégica é definida, portanto, como um documento que reúne "propostas técnicas", produzidas por equipes de especialistas nomeadas pelos países-membros para este fim específico, a serem "executadas" sobre os territórios amazônicos de países signatários.

Os produtos mais relevantes na história do TCA e da OTCA, não obstante, têm sido as declarações e resoluções produzidas por suas instâncias diplomáticas. As primeiras constituem um formato inicialmente acionado apenas pela instância máxima prevista no texto do tratado, a MRE, servindo para declarar intenções e posicionamentos mais gerais diante da comunidade internacional, mas também passaram a ser adotadas quando os presidentes dos países signatários se reuniram, em caráter extraordinário, para reafirmar o acordo, reforçando sua importância política. As resoluções, por sua vez, registram o que se resolve ser feito, sendo produzidas como anexo das atas das reuniões das instâncias MRE e CCA. Somente MRE e CCA geram esse tipo de documento, ainda que as decisões tomadas cheguem a elas após negociação em outras instâncias. Os assuntos e os desdobramentos das decisões inscritas nas resoluções variam bastante. Algumas definem questões ou fundamentam autorizações de ações de considerável interesse político e estratégico. Afinal, 
o que esses documentos reúnem são certos entendimentos e projeções sobre a região amazônica e a respeito do poder do Estado sobre seus territórios e populações. As instâncias diplomáticas compõem a OTCA em conjunto com a SP, apesar da aparência predominante de organismo executor que prevalece quando se pensa em uma organização internacional.

Isso tudo nos permite observar como cada ato de enunciação possui efeitos producentes que, ao se somarem e se unirem a outros procedimentos, formam um todo institucionalizado praticamente irretratável a partir do qual se permite exercer uma autoridade. Uma das mais importantes implicações da produção formal e material de diferenciação das organizações internacionais em relação aos países que a instituem é a construção da imagem de um organismo interestatal que está acima e fora do "Estado", mas que, apesar disso, abarca os seus territórios, conjugando a ideia de Estado espacial e escalar que se projeta, também, “para cima” (FERGUSON; GUPTA, 2002).

\section{A FABRICAÇÃO DA IDEIA DE UMA ATUAÇÃO TÉCNICA, AUTÔNOMA E DESPOLITIZADA}

O que justifica a concepção de um novo e distinto sujeito internacional é a projeção de sua atuação sobre o que se considera serem "objetivos internacionais", ou seja, o "reconhecimento da necessidade de desempenhar tarefas internacionais", "diversas das tarefas que seus membros (os Estados) podem desempenhar", algo capaz de validar também a criação de um aparato burocrático próprio para além dos aparatos nacionais e o estabelecimento das associações contratuais acima elencadas (LAMY, 2015, p. 82).

No caso da OTCA, embora sua atuação seja condensada em termos de promoção do desenvolvimento sustentável e da proteção ambiental, são vários os temas de cooperação contemplados pelo texto do Tratado de Cooperação Amazônica (TCA) que lhe dão origem, ou seja, diversos os motes passíveis de serem explorados por essa Organização: uso e aproveitamento racional de recursos naturais; utilização de recursos hídricos e navegação fluvial; aproveitamento da fauna e flora; serviços de saúde envolvendo melhoria de condições sanitárias e combate de epidemias; investigação científica e 
tecnológica; infraestrutura de transportes e comunicações; emprego racional de recursos humanos e naturais; comércio transfronteiriço; incremento de correntes turísticas vinculado à proteção de culturas indígenas e de recursos naturais; conservação de riquezas etnológicas e arqueológicas; intercâmbio de informações; e, finalmente, estudos para elaboração de projetos comuns (TRATADO DE COOPERAÇÃO AMAZÔNICA, 2017). Os projetos desenvolvidos pela OTCA através de sua Secretaria Permanente devem, portanto, estar relacionados a pelo menos um desses temas. Esses assuntos fundamentam as propostas de ação delineadas em uma Agenda Estratégica ${ }^{12}$, documento referencial da Organização que conjuga questões que podem vir a ser contempladas nas "propostas", "iniciativas", "acordos", "programas" e "projetos" elaborados no âmbito da OTCA.

As tarefas atribuídas às organizações internacionais podem ser desempenhadas tanto por seu corpo técnico/burocrático próprio quanto por meio de articulações que envolvam as estruturas técnicas e burocráticas existentes dos Estados Nacionais ou de outros organismos de cooperação. Na OTCA há quatro categorias de admissão de funcionários para cumprir as incumbências ligadas à sua Secretaria Permanente: os chamados "funcionários executivos", contratados por indicação dos países-membros; os "funcionários admitidos localmente", oriundos de concurso público; e os "consultores" e "peritos externos". Esses dois últimos grupos são de especialistas técnicos empregados pontualmente pela própria OTCA ou designados por organismo internacional, setores e órgãos de governos nacionais ou organizações não governamentais, na esfera de um programa ou acordo de cooperação. No entanto, essas categorias explicitamente contempladas no Regulamento de Pessoal da Secretaria Permanente (OTCA, 2012b) abarcam apenas parcialmente sua atuação, uma vez que boa parte da sua estrutura organizacional é composta por órgãos decisórios e consultivos aos quais tal Secretaria é subordinada, constituídos por representantes de alto escalão dos setores diplomáticos dos países-membros. A OTCA, assim, reúne um conjunto heterogêneo e relativamente ocasional de instituições e práticas de administração pública, com diferentes históricos de constituição, modos de operação e filiações temáticas e políticas.

12 Produzida e tornada pública no início dos anos 2010 com o intuito declarado de orientar a atuação da OTCA até 2018. 
Esse "novo" sujeito do direito internacional, a organização internacional, é instituído através de sua concepção como uma "pessoa” (jurídica), responsabilizada e autorizada a atuar pela consecução de certos "objetivos internacionais", criada como resultado de um arranjo definido como adequado para abordar determinadas questões. Vejo a criação de uma organização internacional como um recurso simbolicamente eficaz da linguagem política, para agregar, em torno de uma questão específica e declarada, múltiplas práticas e atores relacionados à administração pública, sob uma designação personificadora e despolitizadora, sobre a qual se projetam determinadas formas de agência. A percepção de sua efetividade como agente está, portanto, relacionada à operação de práticas em conjunção com a ideia produzida de sua autoridade, como, por exemplo, a adoção de uma discursividade que se manifesta em termos de planos, programas e projetos, algo que defino como uma performance de organismo executor de políticas.

Consoante com tal interpretação de sua existência é produzida uma expectativa de eficácia, no sentido de tornar "concretos" os compromissos enunciados em seu âmbito, sejam estes considerados como princípios originadores dessas composições ou traduzidos em termos presumidamente mais operacionais, sob a forma de projetos. As atuações das organizações internacionais, de forma geral, vêm sendo avaliadas a partir e através de seus próprios enunciados - as análises avaliativas funcionando como uma espécie de reafirmação de seus objetivos declarados como questões públicas ${ }^{13}$-, bem como a partir da projeção de uma ideia a respeito do que deveria significar a existência de um organismo de administração pública definido como internacional e interestatal ${ }^{14}$.

Examinando a atuação da OTCA através de um projeto específico presente em sua Agenda Estratégica, que propunha a criação de roteiros turísticos transnacionais envolvendo alguns de seus países-membros com a finalidade

\footnotetext{
13 O pressuposto e o objeto do que estou chamando de análises avaliativas são as políticas estatais vistas como plano de ação para guiar decisões, representadas, portanto, como resultado da capacidade do Estado de resolver problemas públicos (BLÁZQUEZ, 2012). Entendo que as noções de desempenho e eficácia (ou ineficácia) de atuação concebidas nesse registro são parte de um conjunto de ideias que se produz sobre o "Estado".

${ }_{14}$ Sobre a performance da eficácia no que diz respeito à gestão para o desenvolvimento e para a preservação ambiental da região amazônica, seria interessante refletir acerca de quem são os outros agentes atuantes nesse mesmo campo e que reivindicam para si esse lugar de eficácia.
} 
de promover desenvolvimento e integração regional, foi possível perceber, a despeito do que se poderia supor serem as ações necessárias à execução de um projeto desse tipo, a predominância da operação de procedimentos de nomeação, renomeação, apropriação e reconfiguração de ações e iniciativas já existentes no território. Observando tais resultados em paralelo com análises avaliativas já produzidas sobre a OTCA, ou sobre o arranjo de cooperação em operação desde a assinatura do TCA antes mesmo da criação da Organização, nota-se a recorrência de análises de falta de efetividade, indicando uma série de contradições entre seus objetivos declarados e ações desempenhadas, que, em última instância, evocam a moralmente sentenciada - mas não por isso menos habitual - imagem das promessas políticas não cumpridas. Neste caso específico, trata-se de promessas políticas sobre o desenvolvimento e proteção ambiental da Amazônia, a qual tem sido simbolicamente construída como um "bem comum global" a ser preservado em nome do futuro da humanidade, o que sem dúvidas remete ao dever cívico de postular o seu justo cumprimento, seja no tom de denúncias, seja no tom de pareceres e recomendações.

Optei, entretanto, por encaminhar minhas indagações em outros sentidos, colocando em perspectiva, por exemplo, as questões que chegam a ser enunciadas como "objetivos internacionais" sob o poder resolutivo desses entes, as organizações internacionais ${ }^{15}$. Quais são as implicações de definir tais demandas como problema internacional e de criar um organismo para abordá-las de forma explícita, como uma questão em si? Percebo que a existência de um órgão interestatal voltado para o seu tratamento põe em cena o reconhecimento formal daquela questão como sendo de Estado. São setores, cargos, organogramas, estruturas que, quando estabelecidos, dão corpo à ideia de administração pública e ao seu perímetro de atuação. As formas administrativas do cotidiano, ou seja, a estrutura burocrática que compõe o Estado e seu sistema, servem, nesse caso, não apenas para executar tarefas relacionadas aos seus objetivos declarados, para realizar os seus projetos, mas também para manter a performatividade dos enunciados, ou seja, para

\footnotetext{
${ }_{15}$ O antropólogo Paulo de Góes Filho (2006), ao analisar o lugar da missão do Brasil e de seus agentes na ONU, observa que funcionários técnicos internacionais e diplomatas têm disputado lugar e poder de definição de questões públicas internacionais, aparentemente evidenciando uma divisão entre atuação técnica e política na esfera internacional.
} 
gerar e sustentar sua autoridade como setor operante do Estado ${ }^{16}$. A própria forma como os objetivos são especificados merece atenção, posto que afirmados como obviamente desejáveis e exequíveis, além de relacionados a propósitos aparentemente universais, como o desenvolvimento, a cooperação e a preservação do meio ambiente. A existência e a manutenção do pleno funcionamento de uma organização internacional - comprovada, por exemplo, através de reuniões diplomáticas e da execução de projetos estratégicos - são consideradas um indício da capacidade de seus países-membros de cooperar e produzir consenso para a "gestão transnacional" de um território amplamente disputado, da habilidade de tratar e resolver as questões definidas como problemas públicos que atravessam fronteiras nacionais.

Através do tratamento de temas muito variados, mesmo os mais periféricos, como o turismo - mote do projeto analisado -, as atuações no âmbito do TCA e da OTCA são centradas na defesa da soberania nacional. Isso significa a legitimação jurídica do exercício de poder de governo sobre um determinado território. Além disso, só podem ser entendidas quando situadas em um cenário mais amplo de disputas pelo exercício de poder de governo sobre a Amazônia, sobre seus territórios, populações e recursos. Os enunciados em defesa da soberania são conjugados com práticas e processos específicos que produzem e reforçam a ideia de Estado Nacional soberano, em um domínio bastante caro para a configuração política moderna, que é o das relações internacionais, o que analiso cruzando a proposta de performance de Estado ${ }^{17}$

\footnotetext{
${ }^{16}$ O uso que faço da categoria analítica "performance" tem a ver com um certo desempenho de si, no sentido de exercer um determinado papel quando se age como ou em nome do "Estado". Trata-se de uma utilização fundamentalmente diferente do seu uso no contexto das análises avaliativas em política e economia, que também falam em performance, porém se referindo a outro tipo de desempenho, qual seja, a eficácia da atuação como agente de administração ou desenvolvimento, ou, melhor dizendo, à adequação entre objetivos declarados ou esperados e os resultados obtidos (GOMES, 2011).

17 Para tratar de performances de Estado, Blázquez (2012) parte das elaborações de Debord (1999), conceituando a performance como "uma relação social entre as pessoas mediatizada pelas representações de ações dramáticas” (DEBORD, 1999, n. p. apud BLÁZQUEZ, 2012, p. 45). Neste mesmo sentido, o espetáculo também adquire novos significados, como uma tradução em termos materiais de uma visão de mundo (Weltanschauung), ou seja, não como engano ou falsa realidade, e sim como efetivação de um modo de pensar. Blázquez (2012) examina uma série de eventos de caráter excepcional, as vernissages de um museu de arte público, em que o "Estado" se materializa de duas formas principais: na produção de redes de relações sociais entre pessoas dentre as quais se destacam funcionários públicos e também como representação ou como imagem. Nesse sentido, o autor destaca a magia do "Estado" (conforme TAUSSIG, 1997), que se autorreproduz e se representa como um agente racional nos processos sociais, comentando que esta "pode ser entendida como efeito performativo de 'performances de Estado"' (BLÁZQUEZ, 2012, p. 54).
} 
de Blázquez (2012), elaborada a partir da observação de atos cerimoniais e extraordinários, com a perspectiva de Mitchell (2006), que destaca a reprodução da ideia de Estado nos atos mais cotidianos da administração pública.

Neste sentido, como adiantei no início deste artigo, entendo que o que está sendo produzido com a atuação da OTCA não são apenas "efeitos concretos" de projetos específicos, conforme seus objetivos declarados, quando o são. O que está sendo produzido através da criação e da atuação de uma organização internacional interestatal como a OTCA é a própria ideia de Estado.

\section{DISPOSITIVOS DE PRODUÇÃO SIMBÓLICA DO PODER DO ESTADO}

Uma pesquisa não exaustiva em mecanismos de busca acadêmicos retorna como primeiros e principais resultados ao termo "tratado internacional" (ou, em inglês, "international treaty") estudos sobre tratados internacionais recentes em direitos humanos ou meio ambiente. Assim como o TCA, documento que deu origem à OTCA, estes parecem conter compromissos estatais para a consecução de finalidades específicas, mas, como venho buscando demonstrar, os debates públicos sobre o direito ao desenvolvimento e sobre o seu equilíbrio com a preservação ambiental representam não apenas fonte de interesse em si, mas algo possível de ser enunciado legitimamente para êxito de outros tipos de objetivos, dentre os quais destaco principalmente o de legitimação jurídica do exercício de poder sobre um determinado território.

Como instrumento conceitual, o TCA define publicamente os os jogadores oficiais envolvidos no jogo governamental relativo à Amazônia, simula uma imagem de unidade sobre cada país implicado nele e ainda cria a ideia de um sistema perfeito de integração que poderia ser alcançado a qualquer momento - a impossibilidade de que isso aconteça é vista sempre como resultado de "erros recentes"18. Assim, o TCA e, consequentemente, a OTCA, encarnam e produzem a ideia de uma forma de governo hábil, e não só de

${ }_{18}$ Para uma reflexão sobre a instrumentalidade conceitual de tratados e o Estado teatro, ver Geertz (1991). 
gestão competente, se entendemos governo como técnicas e dispositivos de exercício de poder, sendo o Estado moderno uma de suas formas (FOUCAULT, 2008, 2006). Além disso, as análises avaliativas internas e externas que colocam em questão sua eficácia em termos técnicos, apesar de aparentemente contestarem essa percepção, em verdade a reforçam, ao elaborarem o argumento de que a falta de êxito de seus objetivos declarados é produto de "falhas" que poderiam vir a ser "corrigidas", bastando para isso "vontade" e "comprometimento" dos países envolvidos.

Com a proposta de análise dessas contradições faz-se necessário pensar tais práticas aparentemente discrepantes não em contraposição, mas em correlação. Ao observá-las em conjunto, é possível compreender, por exemplo, que o discurso não é o contraponto da ação, mas a própria efetuação de uma ação que, em determinadas circunstâncias, tem como resultado a produção de um domínio retórico com grandes chances de se desdobrar em outros tipos de domínios, de caráter conceitual ou no âmbito da "prática".

É preciso, ainda, colocar em perspectiva a figuração mítica do "Estado" e seus setores como seres detentores, em si, de um poder essencial e originário. Essa percepção tem como respaldo toda uma estrutura discursiva estatal, materializada em registros escritos, como é o caso dos tratados internacionais. Aplicada ao universo das relações internacionais, essa ideia mitificada leva à crença em um mundo atemporalmente dividido entre Estados soberanos que se relacionam diplomaticamente numa arena internacional. As questões pactuadas nos tratados internacionais têm como pressuposto essencial o domínio dessas formas políticas de governo sobre territórios e populações. Trata-se não simplesmente de uma ideia, mas de uma abstração que sustenta uma complexa estrutura jurídico-política. Vejo a criação e a manutenção de uma instância burocrática interestatal como alicerce de todo um conjunto de performances de Estado ao performatizar a sua solidez e a sua concretude.

Assim, o que quero dizer é que, para além das dimensões de atuação declaradas, realizadas através de trabalhos mais ou menos visíveis das instâncias oficiais, há ainda uma gama de efeitos instrumentais resultantes de procedimentos. É importante mantê-los e relacioná-los à produção e à permanência da legitimidade do poder do Estado sobre territórios e populações. Quando falo de efeitos instrumentais, estou fazendo referência à noção explorada por Ferguson (2006), mas, diferentemente do autor, não demonstro o estabeleci- 
mento em nível local e/ou regional de estruturas administrativas estatais, que não é o principal tipo de efeito produzido pelo TCA ou pela OTCA. Analiso um tratado e um organismo cujos procedimentos centrais são de atuação sobre ideias, portanto, discuto o que - e como - essas ideias produzem sem dizer que estão produzindo. Busco demonstrar que sorte de coisas a sua formulação e enunciação tomam como pressupostos, que, ao serem (re)afirmados, têm seu caráter de verdade sancionado. Minha intenção é saber, portanto, como um determinado conjunto de afirmações enunciadas a partir de um certo arranjo institucional interestatal se articula para produzir, em conjunto com outros procedimentos operados por outros setores da administração pública, o poder do Estado, soberano, escalar e espacialmente abrangente.

Trata-se de uma perspectiva que contraria concepções amplamente estabelecidas e operantes nesse campo de relações. Nas elaborações conceituais definidas como uma teoria das organizações internacionais ${ }^{19}$ conectada ao campo das relações internacionais, a criação de organizações internacionais, ou seja, a fabricação de autoridades transnacionais e interestatais, tem sido considerada algo que essencialmente contraria o poder soberano do Estado. De acordo com essa forma de abordar as organizações internacionais, tem-se entendido que a concepção desse novo e excepcional ${ }^{20}$ sujeito foi resultado de um complexo processo que envolve, ao mesmo tempo, os movimentos aparentemente opostos de ampliação e restrição de poderes estatais: a emergência de um novo sujeito público (inter)estatal estende a autoridade do Estado sobre questões consideradas mais amplas que as nacionais; ao mesmo tempo, esse movimento "perturba" o encadeamento de vontades soberanas de seus "atores principais" (LAMY, 2015).

Com a ideia de que as organizações internacionais se tratam de "novos" sujeitos de um sistema internacional, criadas através de "adesão voluntária”, reforça-se a concepção de uma esfera de relações em que os sujeitos políticos por excelência são os "Estados”, unidades políticas análogas e teoricamente dotadas de direitos iguais, e engendra-se a ideia de que há autonomia dos pa-

\footnotetext{
19 Para uma análise da OTCA sob a perspectiva de uma Teoria Geral das Organizações Internacionais, ver Lamy (2015).

${ }^{20}$ A ideia de sua "excepcionalidade" se dá em relação ao que anteriormente era considerado o sujeito primordial desse campo - o "Estado". Em termos quantitativos, o formato se proliferou, e atualmente existem incontáveis organizações internacionais intergovernamentais em atuação no mundo.
} 
íses em relação às instituições interestatais e vice-versa. A soberania nacional tomada como um dado a partir do qual se desenvolvem as relações internacionais, ou seja, como uma propriedade dos Estados Nacionais, é elemento fundamental no processo de concepção dos países como unidades políticas singulares e absolutas, mas limitadas pela coexistência e pela inter-relação, sem implicar, pelo menos conceitualmente, subordinação ou dependência de umas em relações às outras (FOUCAULT, 2008).

Ao analisar a formação de um sistema mundial e a concepção da doutrina e das instituições do desenvolvimento, Rist (2010) expõe a relação entre a criação das organizações internacionais contemporâneas e o estabelecimento de uma ordem política baseada na noção de que todos os países são formalmente iguais, incluindo os Estados pós-coloniais, tendo sido esta noção estabelecida através da atuação política dos Estados Unidos após a Segunda Guerra. O autor explora como as premissas de desenvolvimento (e o seu complementar, o subdesenvolvimento) e cooperação internacional, centrais a muitas dessas organizações, permitiram atribuir novos estatutos morais e jurídicos às intervenções sobre populações e territórios dos países do assim chamado terceiro mundo. Segundo o autor, foi necessária a criação de novas organizações internacionais, como o Programa das Nações Unidas para o Desenvolvimento (PNUD), e o estabelecimento de novas formas de administração econômica, que fizeram com que a produção se tornasse mundial, e o mercado, universal, para que a ideia de interdependência das nações viesse a prevalecer, tal como hoje a entendemos.

No roteiro das organizações internacionais, há uma série de rituais e procedimentos que encenam essa performance e que se sustentam em torno do princípio jurídico da soberania ${ }^{21}$. Na OTCA, sua atuação é pautada pelo no princípio compulsório da unanimidade entre seus países-membros, conforme estipula o artigo XXV do TCA (TRATADO DE COOPERAÇÃO AMAZÔNICA, 2017). O consenso para alcançar a unanimidade de votos prescrita e aprovar medidas é, nesse sentido, visto como um dado, depreendido não apenas dos próprios processos e vontades políticas dos países-membros, mas dos temas estruturantes do tratado - proteção ambiental, desenvolvimento,

\footnotetext{
${ }^{21}$ O antropólogo Gerhard Anders (2005) mostra como tal ficção é construída através de procedimentos burocráticos de duas das principais organizações internacionais no atual sistema global, o Banco Mundial e o FMI.
} 
soberania estatal -, os quais são entendidos (ou pelo menos se intenta produzir tal entendimento) como de interesse incontestável.

No entanto, ao observar os procedimentos operados em seus bastidores, é possível perceber claramente que a produção do consenso é feita através de negociações, concessões e trocas políticas, entre outras coisas, ações que, em geral, não são integralmente registradas em suas declarações e resoluções, produtos de seus rituais públicos de enunciação. É possível verificar, por exemplo, que temas potencialmente conflituosos são evitados, pelo menos em sua face mais pública, de forma que é possível apontar para uma produção discursiva de um consenso ritual. As discordâncias, objeções e até mesmo oposições, também ritualizadas nesse espaço, se dão sem conhecimento público, através de estratégias indiretas e mais sutis, como manter cargos diretivos sem ocupação, postergar indefinidamente a aprovação de um determinado financiamento ou apoio, ou mesmo rejeitá-lo e devolver recursos já recebidos (GADELHA, 2010). De acordo com Gadelha ${ }^{22}$ (2010), o cargo de Secretário Geral, o mais proeminente da organização, ficou vago por mais de um ano, de junho de 2007 a abril de 2008, uma vez que os países não chegavam a um consenso em torno de um nome para a sucessão. É possível observar algumas questões que se impuseram ao processo de produção de consenso na passagem transcrita abaixo, embora outras permaneçam incógnitas:

Ao fim do mandato da Doutora Arteaga [indicada para seu primeiro mandato pelo Equador], em abril de 2007, a Chancelaria equatoriana apresentou seu nome para recondução ao cargo, proposta aceita por Brasil, Peru, Guiana e Suriname, mas vetada pela Colômbia. Justificada pela necessidade de alternância à frente da Secretaria Permanente, a atitude do Governo colombiano deu-se em momento de tensão bilateral com o Equador, que acusava o vizinho de fumigação de glifosato na área fronteiriça, sob o argumento de combate ao plantio de coca, de acordo com Yánez (2007, p. 19). Apresentaram-se, então, candidaturas do Peru, com apoio colombiano, e da Bolívia, incentivada pela Venezuela. Na tentativa de uma solução de compromisso, o Brasil lançou candidatura, a qual, sem obter

\footnotetext{
${ }^{22}$ Gadelha é diplomata do Ministério das Relações Exteriores brasileiro, autor de uma dissertação de mestrado produzida por ocasião do curso de formação no Instituto Rio Branco, que apresenta uma descrição sobre a crise institucional pela qual a Organização passou em meados dos anos 2000.
} 
consenso, seria retirada em 2008, segundo arquivo do DASII/MRE [setor do Ministério das Relações Exteriores responsável pela OTCA no governo brasileiro] (GADELHA, 2010, p. 29).

A unanimidade prescrita, de tal forma, só é alcançada em sua plenitude por se tratar de uma unanimidade ritual, discursiva e muito especificamente voltada à produção de documentos escritos, através dos quais os enunciados se materializam e dão concretude ao arranjo de cooperação. Esta observação não deve ser entendida como se indicasse a inexistência absoluta de concordâncias, mas como um relevo da dimensão ritual do processo de produção de um consenso que se concretiza essencialmente em documentos, sendo o próprio tratado o seu ícone máximo. Os procedimentos de negociação, adequação de termos, omissão de questões mais "políticas", concessões, entre outros que denunciam divergências e conflitos, de certa forma, permanecem à sombra dos documentos mais públicos e notórios. Porém, podem ser observados através dos relatos a respeito do processo de negociação do tratado e de análises de especialistas, bem como através dos próprios documentos produzidos pelas burocracias estatais implicadas, voltados à circulação interna.

\section{CONSIDERAÇÕES FINAIS}

Ao elaborar as reflexões ora apresentadas, procurei não aderir à naturalização da "cooperação" entre países - no sentido moralmente positivado do termo, tal como tem sido mais comumente explorado no campo de relações que descrevo - como uma necessidade em si. Coloco em questão também a naturalização das formas através das quais essa relação se efetua, como a assinatura de um tratado internacional, a criação de uma organização interestatal ou a realização de projetos de "cooperação técnica", ações vistas como consequências quase automáticas da aproximação entre os países envolvidos ou da sua atuação conjunta no cenário internacional. Entendo tais relacionamentos e suas formas como produtos de processos sociais mais amplos. 
Por definição, os territórios amazônicos são localizados entre e além de fronteiras nacionais, e pela expressividade dos "recursos naturais" passíveis de exploração que concentram, tais territórios são pleiteados no interior de uma comunidade internacional, ora como patrimônio nacional, ora como patrimônio mundial. Tais ideias são produto e recurso da disputa que faz com que a "Amazônia" seja tratada como uma questão internacional e, portanto, como um caso de diplomacia: a disputa pelo exercício de poder sobre territórios e populações. A noção de patrimônio, por exemplo, passa a ser utilizada para se referir à Amazônia no processo de produção desse território e de seus recursos como um bem público, o qual deve, portanto, ser governado, permitindo a enunciação de poderes estatais - nacionais, internacionais ou transnacionais - sobre ele.

Para Gupta e Ferguson (2002), o efeito central das novas formas de governamentalidade transnacional não é fazer os Estados fracos (ou fortes), mas reconfigurar suas habilidades de espacializar sua autoridade e delimitar suas afirmações/pretensões de generalidade superior e universalidade, projetadas sobre os territórios e populações governados. É interessante observar as distinções estabelecidas no que diz respeito aos "Estados" que possuem prestígio, poder e influência para idealizar essas novas formas de governamentalidade.

Tais questões são, de certo modo, eliminadas de cena como efeito da própria performance da forma "organização internacional" como entidade situada acima e fora do Estado. Não é fortuito que tal desenho institucional venha se aperfeiçoando e ganhando tamanho relevo em um cenário de emergência de um Estado neoliberal, em que este, supostamente, estaria perdendo poder e espaço. Não obstante, a soberania nacional continua sendo um princípio jurídico central nesse contexto, mantendo operante a ficção de uma convivência pacífica entre unidades políticas análogas e dotadas de direitos iguais, embora os significados e desdobramentos empíricos a ela relacionados estejam em constante processo de produção e transformação. Para que seja tomada como um dado essencial dos Estados e, a partir disso, reafirmada ou inclusive contestada em seus impactos presumidos, a soberania nacional precisa ser constante e repetidamente enunciada - e isso é exatamente o que a perspectiva de análise que postula a inefetividade do TCA ou da OTCA identifica como "reafirmações redundantes". 
No entanto, o que parece permanecer de mais expressivo durante anos de atividade do TCA e da OTCA são os seus enunciados. Ao longo das décadas, estes se repetem, e o próprio ato de enunciá-los, especialmente através de sua inscrição em documentos, é mantido como seu mais importante e recorrente procedimento. O repertório, porém, se constrói a partir de novos léxicos, incorporando noções e categorias que se evidenciam e refletem os cenários políticos de cada momento. Nesse sentido, é possível perceber como enunciados e declarações proferidas no âmbito da OTCA, materializados em documentos e que parecem conter compromissos estatais para a consecução de objetivos específicos podem ser entendidos como parte de uma série de performances de Estado cujo resultado maior é o de produzir a capacidade estatal de enunciar domínios sobre populações e territórios.

\section{REFERÊNCIAS BIBLIOGRÁFICAS}

1. ABBOTT, Kenneth W.; SNIDAL, Duncan. Why States Act through Formal International Organizations. The Journal of Conflict Resolution, Londres; Thousand Oaks, CA; Nova Délhi, v. 42, n. 1, p. 3-32, fev. 1998.

2. ABRAMS, Philip. Notes on the Difficulty of Studying the State. Journal of Historical Sociology, Nova York, v. 1, n. 1, p. 58-89, mar. 1988.

3. ANDERS, Gerhard. Good Governance as Technology: Toward an Ethnography of the Bretton Woods Institutions. In: MOSSE, D.; LEWIS, D. (Eds.). The Aid Effect: Giving and Governing in International Development. Londres: Pluto Press, 2005. p. 37-60.

4. BLÁZQUEZ, Gustavo. Fazer cultura, fazer(-se) Estado: vernissages e performatividade de Estado em Córdoba. Mana, Rio de Janeiro, v. 18, n. 1, p. 37-61, 2012.

5. BRASIL. Ministério das Relações Exteriores. Informação para o Senhor Presidente da República. 4 de março de 1976. Institucionalização do processo político regional amazônico. Brasília, DF: Ministério das Relações Exteriores, 1976. In: FVG CPDOC. AAS mre ai 1977.03.02. Acervo. Rio de Janeiro: FGV, [1977-1979]. Disponível em: http://www.fgv.br/cpdoc/acervo/arquivo-pessoal/ AAS/textual/documentos-referentes-a-proposta-e-institucionalizacao-dopacto-amazonico-durante-a-gestao-de-azeredo-da-silveira-como-ministro-dasrelacoes-exter. Acesso em: 24 maio 2016. 
6. BRASIL. Ministério das Relações Exteriores. Informação para o Senhor Presidente da República. 10 de janeiro de 1978. Descreve os resultados da $1^{a}$ Reunião do “Tratado Amazônico" e traz proposta de texto revisto. Brasília, DF: Ministério das Relações Exteriores, 1978a. In: FVG CPDOC. AAS mre ai 1977.03.02. Acervo. Rio de Janeiro: FGV, [1977-1979]. Disponível em: http://www.fgv.br/ cpdoc/acervo/arquivo-pessoal/AAS/textual/documentos-referentes-a-propostae-institucionalizacao-do-pacto-amazonico-durante-a-gestao-de-azeredo-dasilveira-como-ministro-das-relacoes-exter. Acesso em: 24 maio 2016.

7. BRASIL. Ministério das Relações Exteriores. Tratado de Cooperação Amazônica. [03 de julho de 1978]. Brasília, DF: Ministério das Relações Exteriores, 1978b. Disponível em: http://www.mpf.mp.br/atuacao-tematica/sci/normase-legislacao/tratados/convencoes-meio-ambiente/tratado-de-cooperacaoamazonica.pdf. Acesso em: 08 set. 2019.

8. DAS, Veena. The Signature of the State: The Paradox of Illegibility. In: DAS, Veena; POOLE, Deborah (Eds.). Anthropology in the Margins of the State. Santa Fe: School of American Research Press, 2004.

9. FERGUSON, James; GUPTA, Akhil. Spatializing States: Toward an Ethnography of Neoliberal Governmentality. American Ethnologist, n. 29, v. 4, p. 981-1010, 2002.

10. FERREIRA, Daniela Caruza Gonçalves. Circuitos de uma organização internacional: enunciados e performance de Estado na Organização do Tratado de Cooperação Amazônica (OTCA). 2018. Tese (Doutorado em Ciências Sociais) - Universidade do Estado do Rio de Janeiro, Instituto de Ciências Sociais, Rio de Janeiro, 2018.

11. FERREIRA, Letícia Carvalho de Mesquita. O etnógrafo, o burocrata e o "desaparecimento de pessoas" no Brasil: notas sobre pesquisar e participar da formulação de uma causa. In: CASTILHO, Sergio Ricardo Rodrigues; SOUZA LIMA, Antonio Carlos; TEIXEIRA, Carla Costa. (Orgs.). Antropologia das práticas de poder: reflexões etnográficas sobre burocratas, elites e corporações. 1. ed. Rio de Janeiro: ContraCapa/LACED, 2014. p. 127-149.

12. FVG CPDOC. AAS mre ai 1977.03.02. Documentos referentes à proposta e institucionalização do Pacto Amazônico durante a gestão de Azeredo da Silveira como ministro das Relações Exteriores. Tratam da proposta brasileira aos países amazônicos - Bolívia, Colômbia, Equador, Guiana, Peru, Suriname e Venezuela - de celebração de um tratado para a região abrangendo as áreas de navegação, interconexão rodoviárias, ferroviárias e fluviais, assistência técnica, proteção da flora e fauna, turismo, entre outras; e das negociações em torno da proposta, que se concretizou na assinatura do tratado, no dia 03 de julho de 1978. In: FGV CPDOC. Acervo. Rio de Janeiro: FGV, [1977-1979]. Disponível em: http://www. fgv.br/cpdoc/acervo/arquivo-pessoal/AAS/textual/documentos-referentes- 
a-proposta-e-institucionalizacao-do-pacto-amazonico-durante-a-gestao-deazeredo-da-silveira-como-ministro-das-relacoes-exter. Acesso em: 24 mai. 2016.

13. FOUCAULT, Michel. Governmentality. In: SHARMA, Aradhana; GUPTA, Akhil (Eds). The Anthropology of the State: A Reader. Malden, MA: Blackwell, 2006.

14. FOUCAULT, Michel. Segurança, território, população. São Paulo: Martins Fontes, 2008.

15. GADELHA, Hayle Melim. A OTCA na política externa brasileira: interesse minguante ou utilidade crescente? 2010. Dissertação (Mestrado em Diplomacia) - Instituto Rio Branco, Ministério das Relações Exteriores, Brasília, DF, 2010.

16. GEERTZ, Clifford. Negara: O Estado teatro no século XIX. Lisboa: Difel; Rio de Janeiro: Bertrand, 1991.

17. GOMES, Áureo de Toledo.Questionando o fracasso estatal: um balanço da literatura crítica". BIB: Revista Brasileira de Informação Bibliográfica em Ciências Sociais, São Paulo, n. 71, p. 69-94, 2011.

18. GÓES FILHO, Paulo de. O clube das Nações: a missão do Brasil na ONU e o mundo da diplomacia parlamentar. 1. ed. Rio de Janeiro: Relume Dunará, 2003.

19. LACERDA, Paula. Meninos de Altamira: violência, "luta" política e administração pública. Rio de Janeiro: Garamond, 2015.

20. LAMY, Marcelo. A Organização do Tratado de Cooperação Amazônica sob a perspectiva da teoria geral das organizações internacionais. In: SILVA, Fernando Fernandes da. (Org.) A proteção da sociobiodiversidade da Amazônia e o Tratado de Cooperação Amazônica: análises e reflexões. São Paulo: Peirópolis, 2015.

21. LI, Tania Murray. The Will to Improve: Governmentality, Development, and the Practice of Politics. Durham, NC: Duke University Press, 2007.

22. LUGONES, Maria Gabriela. La BUENAS PRACTICAS como tecnología de gobierno en la Córdoba contemporânea. 8 jun. 2017. In: CONGRESO DE ANTROPOLOGÍA EN COLOMBIA, 16; CONGRESO ASOCIACIÓN LATINOAMERICANA DE ANTROPOlOGÍA, 5., 2017, Bogotá. Políticas de los conocimientos y las prácticas antropológicas en América Latina y el Caribe. 2017.

23. MITCHELL, Timothy. Society Economy and the State Effect. In: SHARMA, Aradhana; GUPTA, Akhil (Eds). The Anthropology of the State: A Reader. Malden, MA: Blackwell, 2006.

24. ORGANIZAÇÃO DO TRATADO DE COOPERAÇÃO AMAZÔNICA. OTCA. Agenda Estratégica de Cooperación Amazónica. Aprobada en la X Reunión de 
Ministros de Relaciones Exteriores del TCA. Noviembre 2010. Brasília, DF: OTCA, 2010. Disponível em: http://www.otca-oficial.info/assets/documents/20160629/ bfa5dfe5a1ca92b4efdb102ee8e54634.pdf. Acesso em: 10 mar. 2018.

25. ORGANIZAÇÃO DO TRATADO DE COOPERAÇÃO AMAZÔNICA. OTCA. Protocolo de Enmienda al Tratado de Cooperación Amazónica In: ORGANIZAÇÃO DO TRATADO DE COOPERAÇÃO AMAZÔNICA. OTCA. Base jurídica del Tratado de Cooperación Amazónica. Actualización resumida 2003-2012. Brasília, DF: OTCA, 2012a. Disponível em: http://www.otca-oficial. info/assets/documents/20160629/832921b9594e07e68ae42b64a7e4238e.pdf. Acesso em: 10 jun. 2014.

26. ORGANIZAÇÃO DO TRATADO DE COOPERAÇÃO AMAZÔNICA. OTCA. Reglamento del personal de la Secretaría Permanente de la Organización del Tratado de Cooperación Amazónica. In: ORGANIZAÇÃO DO TRATADO DE COOPERAÇÃO AMAZÔNICA. OTCA. Base jurídica del Tratado de Cooperación Amazónica. Actualización resumida 2003-2012. Brasília, DF: OTCA, 2012b. Disponível em: http://www.otca-oficial.info/assets/documents/20 160629/832921b9594e07e68ae42b64a7e4238e.pdf. Acesso em: 10 jun. 2014.

27. ORGANIZAÇÃO DO TRATADO DE COOPERAÇÃO AMAZÔNICA. OTCA. Resolución RES/X MRE-OTCA/5, de 30 de novembro de 2010. In: ORGANIZAÇÃO DO TRATADO DE COOPERAÇÃO AMAZÔNICA. OTCA. Base jurídica del Tratado de Cooperación Amazónica. Actualización resumida 2003-2012. Brasília, DF: OTCA, 2012c. Disponível em: http://www.otca-oficial. info/assets/documents/20160629/832921b9594e07e68ae42b64a7e4238e.pdf. Acesso em: 10 jun. 2014.

28. RIST, Gilbert. The History of Development: From Western Origins to Global Faith. 3.ed. Londres: Zed Books, 2010.

29. TAUSSIG, Michael. The Magic of the State. Londres: Routledge, 1997.

30. TORRECUSO, Paolo. Tratado de Cooperação Amazônica e a Organização do Tratado de

31. Cooperação Amazônica: análise da criação, evolução e eficácia de um regime internacional. 2004. Dissertação (Mestrado em Relações Internacionais) Universidade de Brasília, Brasília, 2004.

32. TRATADO DE COOPERACIÓN AMAZÔNICA. Actas de las reuniones del Grupo de Trabajo ad hoc sobre el Establecimiento de la Secretaria Permanente de la Organizacion del Tratado de Cooperación Amazônica. II Reunión, Lima, 3-4 de junio de 1996. In:

Base jurídica del Tratado de Cooperacion Amazónica. Antecedentes constitutivos de la Organización del Tratado de Cooperación Amazónica (OTCA). La Paz: Secretaría Pro Tempore, 2002. 
33. VIANNA, Adriana. Etnografando documentos: uma antropóloga em meio a processos judiciais. In: CASTILHO, Sergio Ricardo Rodrigues; SOUZA LIMA, Antonio Carlos; TEIXEIRA, Carla Costa. (Orgs.). Antropologia das práticas de poder: reflexões etnográficas sobre burocratas, elites e corporações. 1. ed. Rio de Janeiro: ContraCapa/LACED, 2014. p. 43-70.

Recebido em 04 de agosto de 2018

Avaliador A: 04 de setembro de 2018

Avaliador B: 29 de setembro de 2018

Aceito em 13 de novembro de 2018 